\title{
Super UWB Grooved and Corrugated Antenna for GPR Application
}

\author{
Mohammed Guerroui ${ }^{1 *}$, Abdelhalim Chaabane ${ }^{1}$, Ahcene Boualleg ${ }^{1}$ \\ ${ }^{1}$ Laboratoire des Télécommunications-LT, Département d'Electronique et Télécommunications, Faculté des Sciences et de la \\ Technologie, Université 8 Mai 1945 Guelma, 24000 Guelma, P. O. B. 401, Algeria \\ * Corresponding author, e-mail: guerroui.mohammed@univ-guelma.dz
}

Received: 18 September 2020, Accepted: 20 May 2021, Published online: 03 November 2021

\begin{abstract}
A novel super Ultra-Wideband (UWB) monopole antenna for Ground Penetrating Radar (GPR) application is investigated in this paper. The designed antenna is constructed by a grooved elliptical patch and a corrugated semi-elliptical ground plane. The designed antenna is fabricated on the FR4-substrate that has a compact size of $0.195 \lambda_{0} \times 0.1625 \lambda_{0} \times 0.00975 \lambda_{0}$ at $1.95 \mathrm{GHz}$. The measurements are performed by using a well calibrated R\&S®ZNB Vector Network Analyzer. The measured results show that the fabricated prototype covers a super UWB extending from $1.95 \mathrm{GHz}$ to upper than $20 \mathrm{GHz}(>164.46 \%$ ). Additionally, the voltage standing wave ratio (VSWR) and the gain responses of the antenna are simulated in close proximity to a dry/wet sand box to verify the penetration ability of the antenna. The results are acceptable which guarantee the aptitude of this antenna to operate as a GPR antenna.
\end{abstract}

\section{Keywords}

super Ultra-Wideband (UWB), grooved elliptical patch, corrugated semi-elliptical ground plane, Ground Penetrating Radar (GPR) application

\section{Introduction}

Ground Penetrating Radar (GPR) is one of non-invasive and non-destructive technologies that employ electromagnetic waves for inspecting, examining and analyzing or evaluating the media, materials or all kind of underground surfaces in a variety of disciplines. As the eye of human, an antenna is an essential hardware component that specify the detection performance of a GPR system. Because the profundity of detection is of high importance for practical applications, the broadband characteristic for GPR antennas is required for detection at various depth levels. Nowadays, ultra-wideband (UWB) antennas have found various applications in GPR such as the inspection of sites and the localization of buried structures [1-4]. In this framework, some GPR antennas have been proposed in recent literature such those presented in [5-9]. A heavy horn GPR antenna that has a big size of about $410 \times 300 \times 800 \mathrm{~mm}^{3}$ and that operates in a narrow band extending from $1 \mathrm{GHz}$ to $2 \mathrm{GHz}$ has been proposed in [5]. In [6], a complex Vivaldi antenna operating in a large bandwidth extending from $0.4 \mathrm{GHz}$ to $10 \mathrm{GHz}$ has been presented. However, its big size of about $120 \times 130 \times 10 \mathrm{~mm}^{3}$ is another main drawback that limits its application for GPR detections. A voluminous tapered slot GPR antenna that operates in a wideband ranging from $0.6 \mathrm{GHz}$ to $4 \mathrm{GHz}$ and that has a large size of about $180 \times 220 \times 1.6 \mathrm{~mm}^{3}$ has been proposed in [7]. In [8], a bowtie GPR antenna that operates only between $0.98 \mathrm{GHz}$ and $4.5 \mathrm{GHz}$ and that has a big size of $200 \times 150 \times 40.8 \mathrm{~mm}^{2}$ has been proposed. By presenting the same drawback of the big size, a magnetic loop GPR antenna that operates between $0.1 \mathrm{GHz}$ to $6 \mathrm{GHz}$ and that has large dimensions of $200 \times 225 \times 1.6 \mathrm{~mm}^{2}$ has been proposed in [9]. The main disadvantages of all these presented antennas are the bulky dimensions, the high weigh, and the complexity that limit their integration within the GPR systems. Besides, there is always a need for other efficient and high penetration antennas for various GPR applications. In this paper, a compact super UWB antenna is proposed for GPR application. A set of grooves and corrugations are inserted in the radiating patch and in the ground plane, respectively, to enhance the impedance bandwidth and the impedance matching. A prototype is realized and measured by utilizing a $R \& S^{\circledR} Z N B$ Vector Network Analyzer. A penetration test is established in order to check the usefulness of the 
antenna for GPR application. A good penetration level is obtained which confirms the ability of the antenna to operate as a GPR antenna.

\section{Antenna design and results}

Both the front view and the back view of the designed super UWB antenna are shown in the Fig. 1. The designed antenna is calculated and analyzed by the use of the commercial software CST Microwave Studio $^{\mathrm{TM}}$ [10]. The antenna's evolution during the design stage is illustrated in the Fig. 2. The initial design is a conventional monopole antenna (antenna A) that is constructed by a reduced rectangular ground plane and a rectangular patch. In the second design (antenna B), the rectangular ground plane is replaced by a corrugated semi-elliptical ground plane. In addition, the rectangular patch is replaced by a grooved elliptical patch in the final design (antenna $\mathrm{C}$ ). The designed antenna is fabricated on a low-cost 1.5-mm-thick FR4 substrate that has a relative dielectric constant of 4.4 and a loss tangent of 0.025 . The

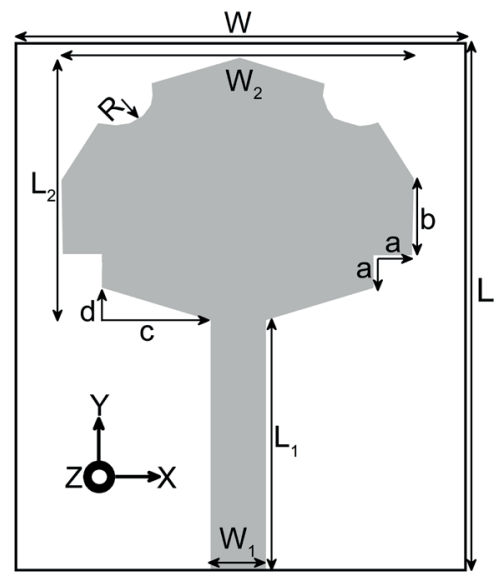

(a)

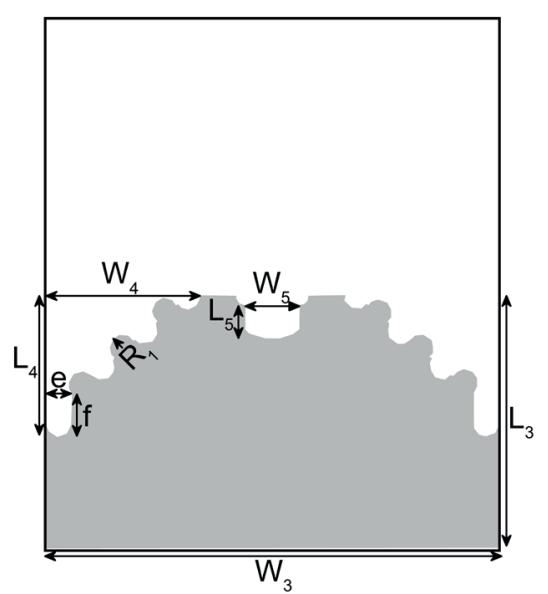

(b)

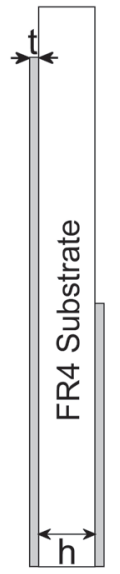

(c)
Fig. 1 Detailed configuration of the proposed super UWB antenna, (a) front view, (b) back view, (c) side view total antenna's size is $0.195 \lambda_{0} \times 0.1625 \lambda_{0} \times 0.00975 \lambda_{0}$ at $1.95 \mathrm{GHz}$. The dimensions of the designed antenna were optimized to ameliorate its performances. They are as follows: $\mathrm{L}=30 \mathrm{~mm}, \mathrm{~L}_{1}=13.5 \mathrm{~mm}, \mathrm{~L}_{2}=16.3 \mathrm{~mm}, \mathrm{~L}_{3}=13 \mathrm{~mm}$, $\mathrm{L}_{4}=6.5 \mathrm{~mm}, \mathrm{~L}_{5}=1.7 \mathrm{~mm}, \mathrm{R}=2 \mathrm{~mm}, \mathrm{R}_{1}=0.7 \mathrm{~mm}, \mathrm{a}=2 \mathrm{~mm}$, $\mathrm{b}=5.1 \mathrm{~mm}, \mathrm{c}=5.6 \mathrm{~mm}, \mathrm{~d}=2 \mathrm{~mm}, \mathrm{e}=2.2 \mathrm{~mm}, \mathrm{f}=1.52 \mathrm{~mm}$, $\mathrm{t}=0.018 \mathrm{~mm}, \mathrm{~h}=1.5 \mathrm{~mm}, \mathrm{~W}=25 \mathrm{~mm}, \mathrm{~W}_{1}=2.8 \mathrm{~mm}$, $\mathrm{W}_{2}=18 \mathrm{~mm}, \mathrm{~W}_{3}=25 \mathrm{~mm}, \mathrm{~W}_{4}=8.75 \mathrm{~mm}, \mathrm{~W}_{5}=3.02 \mathrm{~mm}$.

Fig. 3 shows that the working impedance bandwidth and the impedance matching are highly improved after the use of the corrugated semi-elliptical ground plane and the grooved elliptical patch. As noted in [11], other advantages of introducing cuts in a planar antenna are the reduction of weight and minimizing the conductor losses. Table 1 illustrates the working bandwidths of the three antennas.

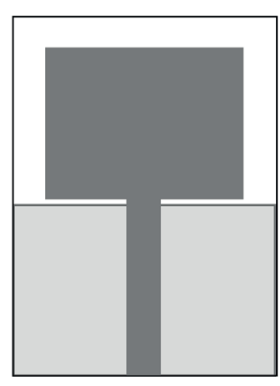

(a)

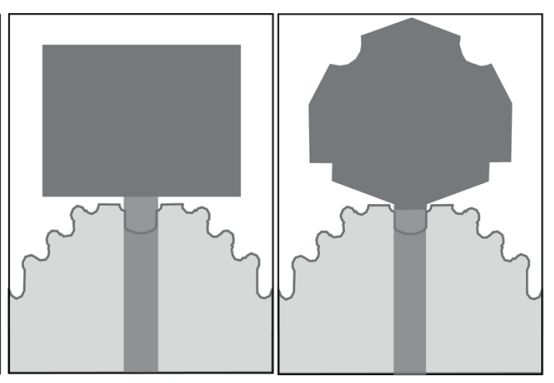

(b) (c)
Fig. 2 Antenna's evolution during the design stage, (a) antenna A, (b) antenna B, (c) antenna C

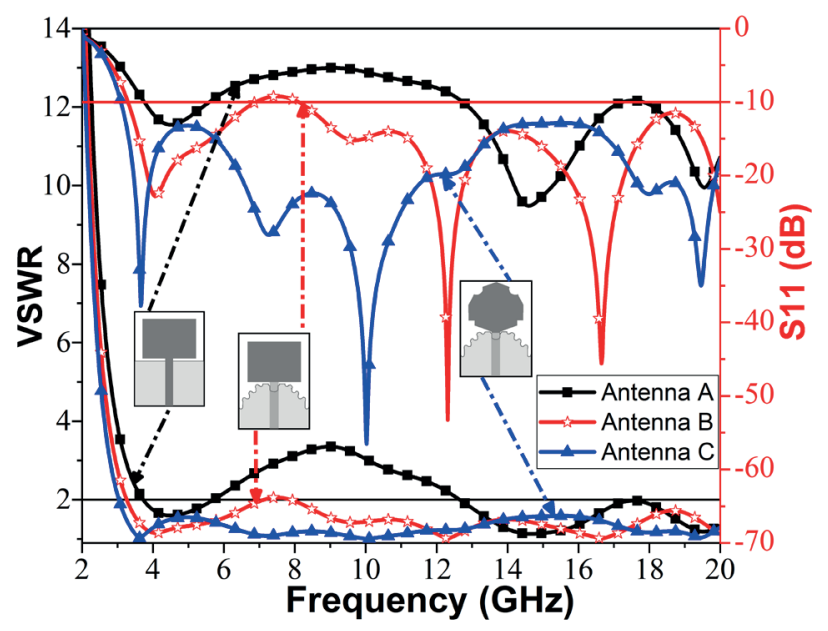

Fig. 3 VSWR and S11 of the different antennas

Table 1 Antennas bandwidth (BW) comparison

\begin{tabular}{lcc}
\hline Antennas & BW $(\mathrm{GHz})$ & BW $(\%)$ \\
\hline Antenna A & $3.69-5.72,12.61->20$ & $43.19,45.32$ \\
Antenna B & $3.26->20$ & $>143.94$ \\
Antenna C & $3.07->20$ & $>146.83$ \\
\hline
\end{tabular}


Fig. 4 indicates that the real part of the impedance is narrowly oscillating around $50 \mathrm{ohms}$ which correspond to the value of the input impedance of the excitation port. Fig. 5 shows a comparison between the accepted power and the undelivered powers (either the power outgoing the port or the power absorbed by the port) by the excitation port. Compared to the provided power, very low wasted powers are revealed throughout the working bandwidth that confirm the good adaptation of the antenna. Whereas, the imaginary part is closely oscillating around zero which indicates the super UWB operation for the designed antenna. The current distributions on the antenna's surface at the frequencies $3.5 \mathrm{GHz}, 7 \mathrm{GHz}$, and $16 \mathrm{GHz}$, are presented in Fig. 6. As the frequency increases, a high current concentration can be visualized on the antenna's surface. A prototype of the designed antenna is fabricated using a laser printer (LPKF S103). The photograph of the fabricated prototype that has a total size of $0.195 \lambda_{0} \times 0.1625 \lambda_{0} \times 0.00975 \lambda_{0}$ at $1.95 \mathrm{GHz}$ is presented in Fig. 7.

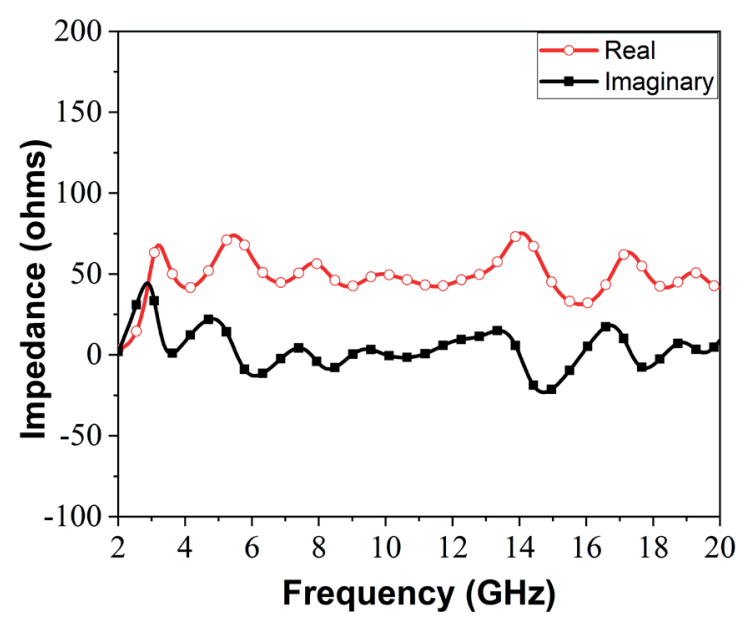

Fig. 4 Real and imaginary parts of the impedance

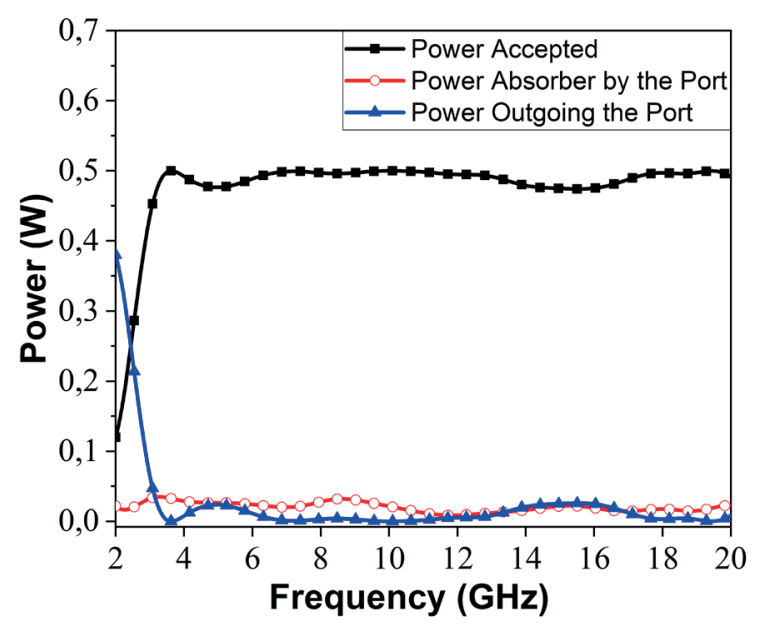

Fig. 5 Powers at the input port of the antenna
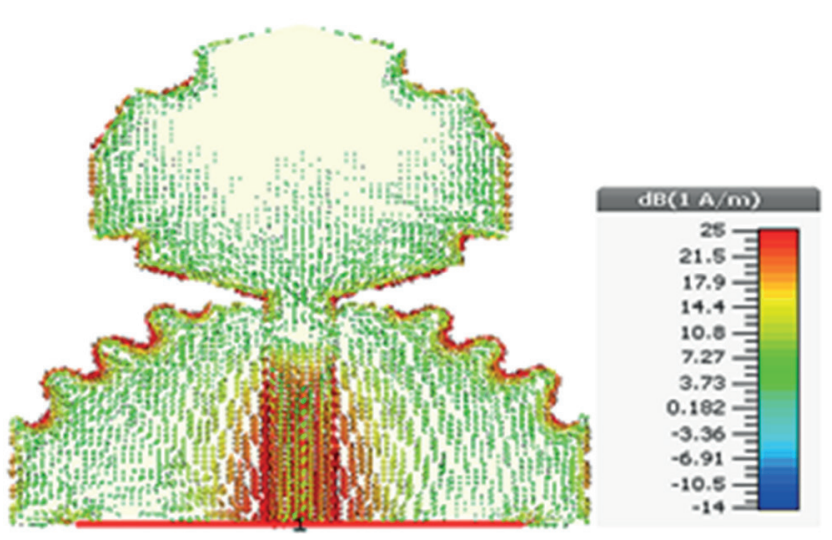

(a)
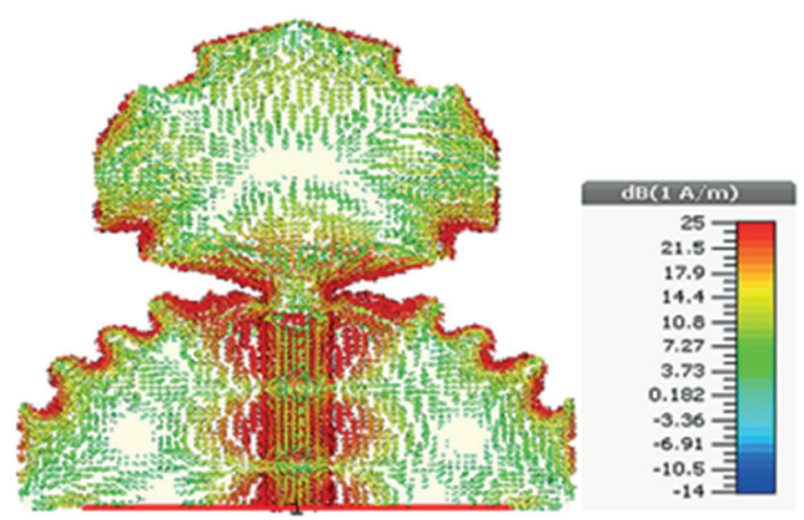

(b)
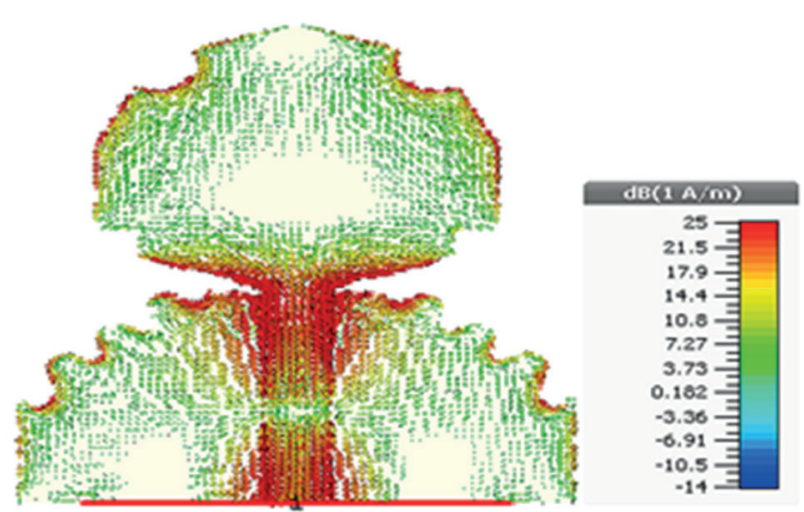

(c)

Fig. 6 Current distribution on the antenna's surface at different frequencies (a) $3.5 \mathrm{GHz}$, (b) $7 \mathrm{GHz}$, (c) $16 \mathrm{GHz}$

The VSWR response of the fabricated prototype was measured and experienced by employing a $R \& S^{\circledR} Z N B$ Vector Network Analyzer. A good agreement between the simulated and the measured results are gotten and the super UWB operation is confirmed. Fig. 8 indicates that the fabricated prototype operates in a super UWB extending from $1.95 \mathrm{GHz}$ to upper than $20 \mathrm{GHz}(>164.46 \%)$ which is wider than the reserved UWB frequency band of $110 \%$ (3.1-10.6 GHz). The simulated co-polar and 


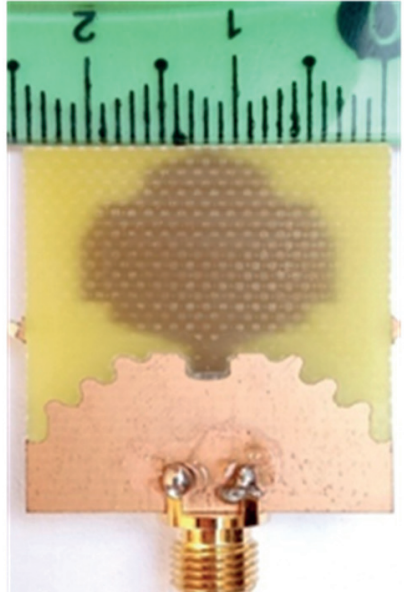

(a)

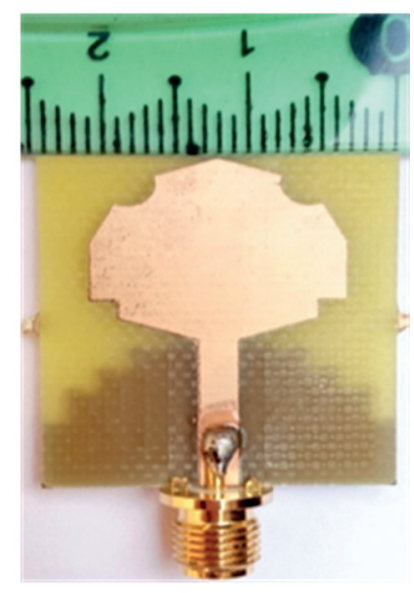

(b)
Fig. 7 Fabricated prototype, (a) front view, (b) back view

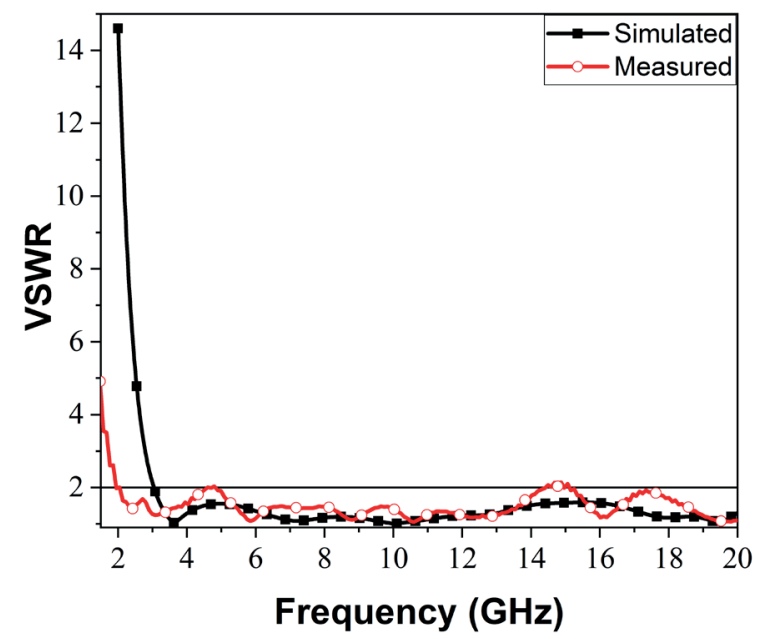

Fig. 8 Measured and simulated VSWR of the proposed antenna

cross-polar radiation patterns of the antenna, in both the $x z$-plane (H-plane) and the $x z$-plane (E-plane) at $3.5 \mathrm{GHz}$, $7 \mathrm{GHz}$, and $16 \mathrm{GHz}$ are presented and compared in Figs. 9 and 10, respectively. As it is shown, the designed antenna has excellent omnidirectional radiation patterns in the $x z$-plane and almost bidirectional in the $x z$-plane, similar appearances are noted in $[12,13]$. Because of the extramodes at upper frequencies, it is observed that the magnitude of the cross-polar in the two planes augments with augmenting the frequency, also this augmentation can be attributed to the excitation of higher-order mode [14]. Moreover, the magnitude of the co-polar component undergoes a feeble distortion in shape at higher frequencies owing to the reflections along the corrugations used in the ground plane and along the borders of the radiating patch; this is confirmed by the high surface current distribution at theses edges (see Fig. 6).

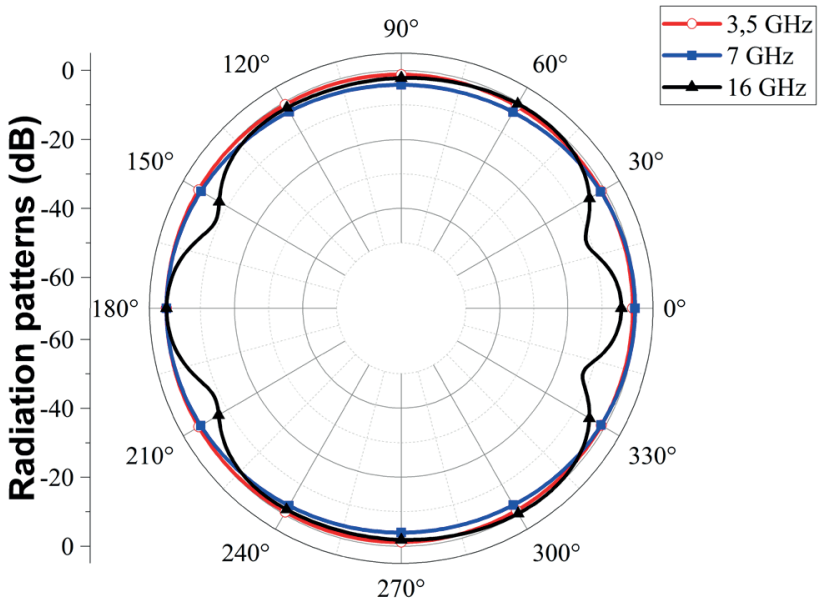

(a)

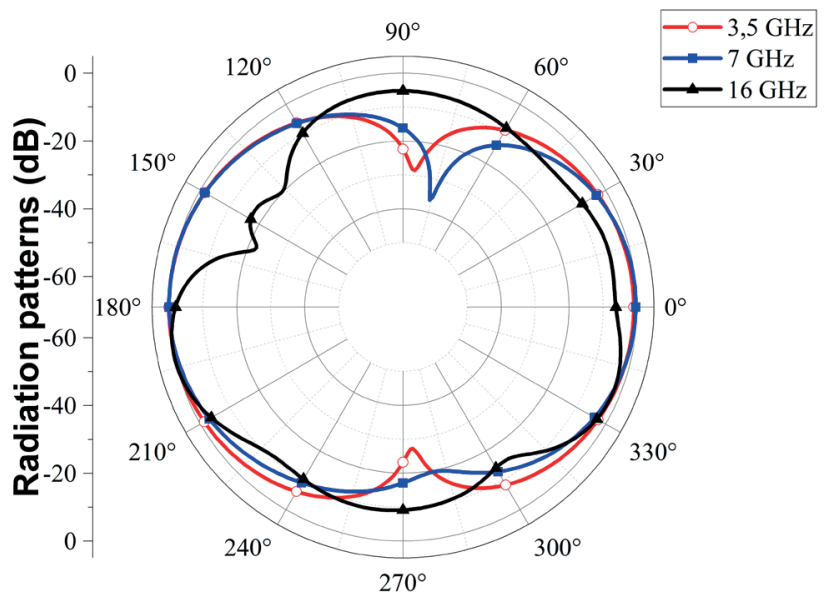

(b)

Fig. 9 Normalized co-polarization radiation patterns at different frequencies, (a) xz-plane, (b) yz-plane

Various UWB GPR antennas have been previously published. Unfortunately, most of these antennas are complex or/and have huge size. In Table 2 [15-18], a comparative analysis is established between the fabricated antenna and some other recent published GPR planar antennas to show its effectiveness for GPR application. It shows that the features and the performances of the fabricated antenna are similar or improved to those of some recent published antennas. Therefore, it could be concluded that our antenna can be a good candidate for GPR application.

\section{Ground penetration test}

In Section 3, a ground penetrating test is established in order to test the penetration ability for the designed antenna. As shown in Fig. 11, the antenna is positioned in a close proximity to a sand test box for combining the electromagnetic waves into the tested sub-surfaces. 


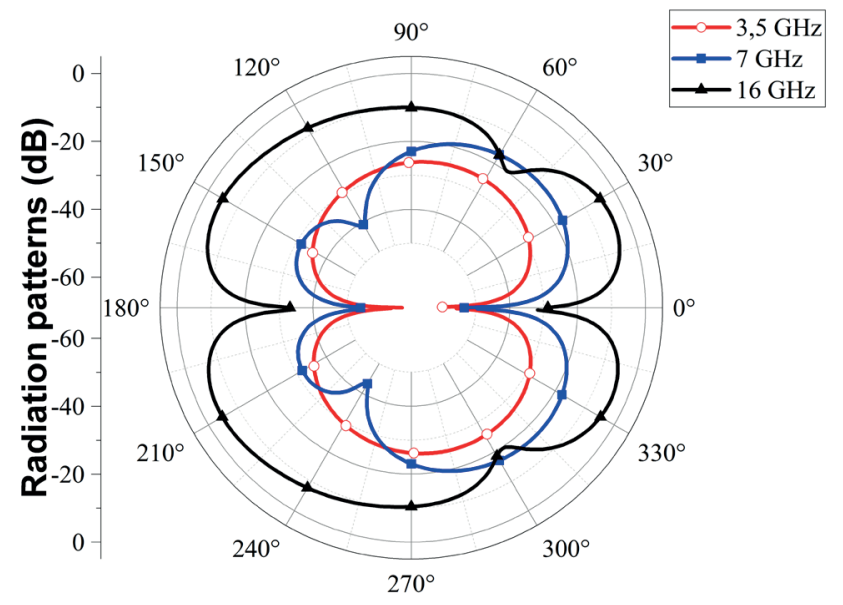

(a)

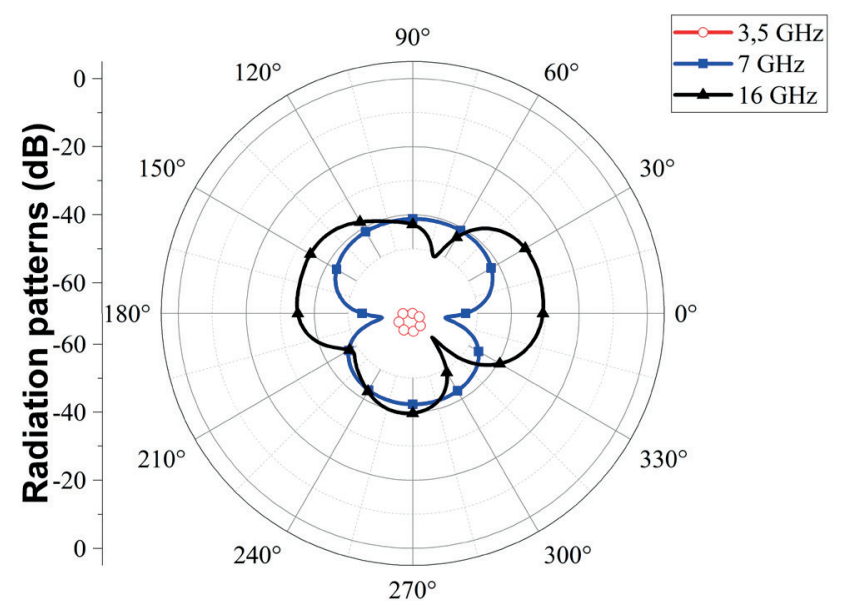

(b)

Fig. 10 Normalized cross-polarization radiation patterns at different frequencies, (a) xz-plane,(b) yz-plane

Table 2 Designed antenna's comparative analysis with some other already mentioned planar antennas for GPR application

\begin{tabular}{lcclc}
\hline Ref. & Substrate & Sizes $\left(\mathrm{mm}^{3}\right)$ & BW $(\mathrm{GHz})$ & BW $(\%)$ \\
\hline$[15]$ & FR4 & $270 \times 235 \times 1.5$ & $0.18-6.2$ & 188.71 \\
{$[16]$} & FR4 & $650 \times 220 \times 1.6$ & $0.099-0.107$ & 7.77 \\
{$[17]$} & FR4 & $360 \times 300 \times 1$ & $0.25-0.75$ & 1 \\
{$[18]$} & FR4 & $230 \times 270 \times 1.6$ & $0.297-3.25$ & 166.51 \\
This work & FR4 & $30 \times 25 \times 1.5$ & $1.95->20$ & $>164.64$ \\
\hline
\end{tabular}

A distance of about $3 \mathrm{~mm}$ between the antenna and the sand test box is kept during the simulation process. The sub-surfaces considered for the penetration test are: the dry sand (that has a relative dielectric constant of 3) and the wet sand (that has a relative dielectric constant of 12). In the first time, the established test box is filled only by a single layer of dry sand of thickness $13 \mathrm{~cm}$ and then a layer of wet sand is added below the dry sand layer; the total size of the considered test bed is $15 \times 15 \times 14 \mathrm{~cm}^{3}$. The thickness of the considered test box of $14 \mathrm{~cm}$ is thicker than the one considered in [19]. As depicted in Fig. 12, good values of VSWR are achieved in the presence of the considered test box indicating a good capability of penetration for the designed antenna. Fig. 13 indicates that the simulated antenna has a reasonable gain which is fluctuating between $2.04 \mathrm{dBi}$ and $4.84 \mathrm{dBi}$ throughout all the working bandwidth. The obtained values are better than

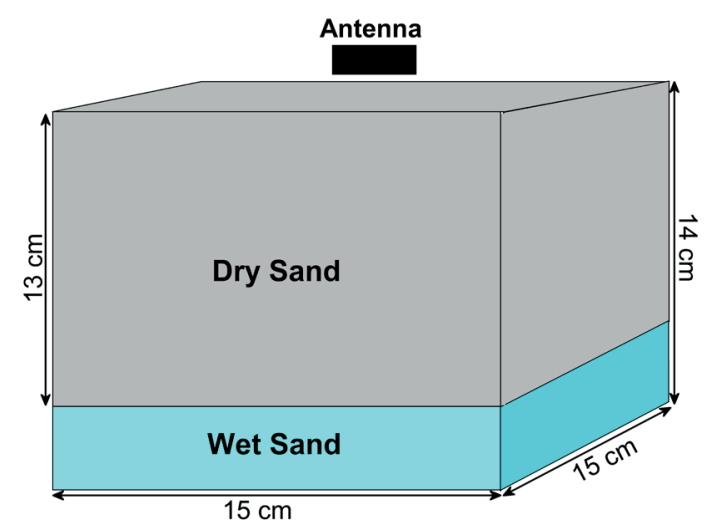

Fig. 11 Diagram of the GPR antenna over the considered test box

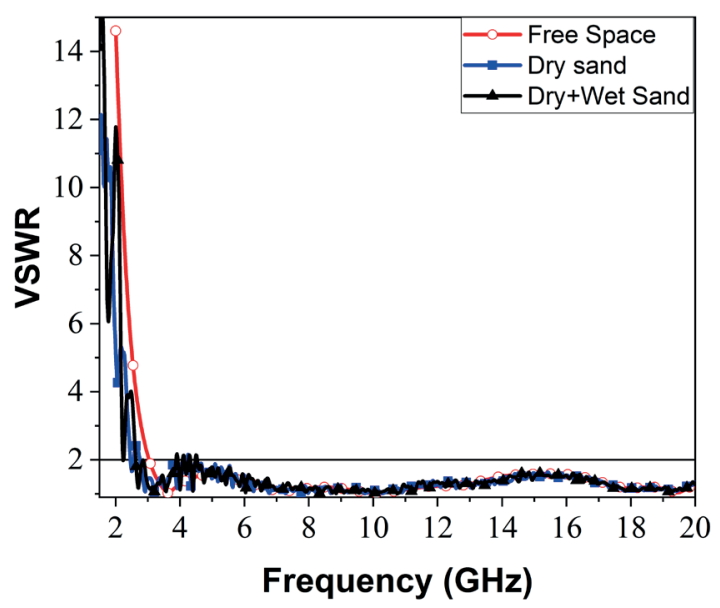

Fig. 12 VSWR in close proximity to the considered test box

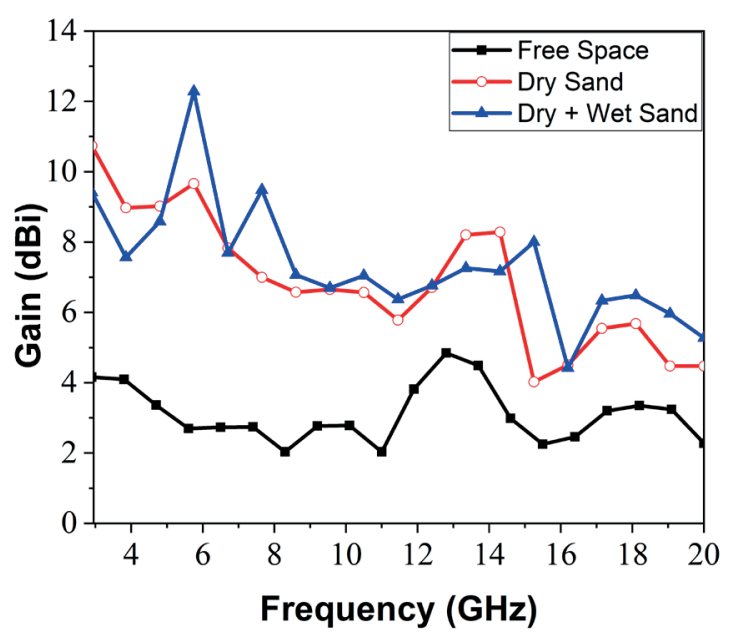

Fig. 13 Gain achieved by the designed antenna 
the ones gained in [20]. Furthermore, in the presence of the sand test box the gain of the designed antenna has high values especially in the low frequencies below $12 \mathrm{GHz}$.

\section{Conclusion}

A new compact printed super UWB monopole antenna for GPR application is designed and fabricated. The operating bandwidth and the impedance matching are improved after introducing the grooved elliptical patch and the semi-elliptical ground plane. The measured bandwidth extends from $1.95 \mathrm{GHz}$ to upper than $20 \mathrm{GHz}(>164.46 \%)$, covering tremendously the unlicensed UWB frequency band. The penetration capability of the designed antenna is checked throughout a dry/wet sand box to verify its capability to

\section{References}

[1] Seyfried, D., Jansen, R., Schoebel, J. "Shielded loaded bowtie antenna incorporating the presence of paving structure for improved GPR pipe detection", Journal of Applied Geophysics, 111, pp. 289298, 2014.

https://doi.org/10.1016/j.jappgeo.2014.10.019

[2] Liu, S., Wang, Q., Gao, R. "A topology optimization method for design of small GPR antennas", Structural Multidisciplinary Optimization, 50(6), pp. 1165-1174, 2014.

https://doi.org/10.1007/s00158-014-1106-y

[3] Hendevari, M. S., Pourzaid, A., Nikmehr, S. "A novel ultra-wideband monopole antenna for ground penetrating radar application", Microwave and Optical Technology Letters, 60(9), pp. 2252-2256, 2018.

https://doi.org/10.1002/mop.31335

[4] Elsaid, M., Mahmoud, K. R., Hussein, M., Hameed, M. F. O., Yahia, A., Obayya, S. S. A. "Ultra-wideband circularly polarized crosseddual-arm bowtie dipole antenna backed by an artificial magnetic conductor", Microwave and Optical Technology Letters, 61(12), pp. 2801-2810, 2019.

https://oi.org/10.1002/mop.31979

[5] Abdelgwad, A. H., Said, T. M. "L-band horn antenna radiation enhancement for GPR by loading wire a wire medium", Microwave and Optical Technology Letters, 59(10), pp. 2558-2563, 2017. https://doi.org/10.1002/mop.30771

[6] Elsheakh, D. N., Abdallah, E. A. "Compact ultra-wideband Vivaldi antenna for ground-penetrating radar detection application", Microwave and Optical Technology Letters, 61(5), pp. 1268-1277, 2019. https://doi.org/10.1002/mop.31724

[7] Raza, A., Lin, W., Chen, Y., Yanting, Z., Chattha, H. T., Sharif, A. B. "Wideband tapered slot antenna for application in ground penetrating radar", Microwave and Optical Technology Letters, 62(7), pp. 2562-2568, 2020.

https://doi.org/10.1002/mop.32338

[8] Joula, M., Rafiei, V., Karamzadeh, S. "High gain UWB antenna bowtie antenna design for ground penetrating radar application", Microwave and Optical Technology Letters, 60(10), pp. 2425-2429, 2018. https://onlinelibrary.wiley.com/doi/full/10.1002/mop.31392 operate as a GPR antenna. Satisfactory results are obtained which consolidate its candidature for GPR application, such as: the inspection and the examination of the sub-surfaces and materials for the detection and the identification of the buried objects. Finally, the reduced size and the circular polarization are ones of the characteristics that to be taking in consideration in the future designs to meet the requirements of the future GPR systems.

\section{Acknowledgement}

This work was supported by the Directorate General for Scientific Research and Technological Development (DG-RSDT) of Algeria.

[9] Raza, A., Lin, W., Liu, Y., Sharif, A. B., Chen, Y., Ma, C. "A magnetic-loop based monopole antenna for GPR application", Microwave and Optical Technology Letters, 61(4), pp. 1052-1057, 2019. https://doi.org/10.1002/mop.31690

[10] Dassault Systèmes "CST Studio Suite, Electromagnetic Field Simulation Software, version 2016", [online] Available at: https:// www.3ds.com/products-services/simulia/products/cst-studiosuite/[Accessed: 28 January 2021]

[11] Chaabane, A., Babouri, A. "Dual Band Notched UWB MIMO Antenna for Surface Penetrating Application", Advanced Electromagnetics, 8(3), pp. 6-15., 2019. https://doi.org/10.7716/aem.v8i3.1062

[12] Puri, S. C., Das, S., Tiary, M. G. "UWB monopole antenna with dualband-notched characteristics", Microwave and Optical Technology Letters, 62(3), pp. 1222-1229, 2020. https://doi.org/10.1002/mop.32112

[13] Chaabane, A., Mahri, O., Aissaoui, D., Guebgoub, N. "Multiband Stepped Antenna for Wireless Communication Applications", Informacije MIDEM - Journal of Microelectronics, Electronic Components and Materials, 50(4), pp. 275-284, 2020. https://doi.org/10.33180/InfMIDEM2020.405

[14] Aissaoui, D., Chaabane, A., Boualleg, A., Guerroui, M. "Coplanar Waveguide-fed UWB Slotted Antenna with Nnotched-band Performance", Periodica Polytechnica Electrical Engineering and Computer Science, 65(1), pp. 69-73, 2021. https://doi.org/10.3311/PPee.15869

[15] Mohanna, M. M., Abdallah, E. A., El-Hennawy, H., Attia, M. A. "A Novel High Directive Willis-Sinha Tapered Slot Antenna for GPR Application in Detecting Landmine", Progress In Electromagnetics Research C, 80, pp. 181-198, 2018. https://doi.org/10.2528/pierc17111904

[16] Howlader, M. O. F., Sattar, T. P. "Miniaturization of Dipole Antenna for Low Frequency Ground Penetrating Radar", Progress In Electromagnetics Research C, 61, pp. 161-170, 2016. https://doi.org/10.2528/pierc15103004 
[17] Li, X., Shao, J., Zhang, Y. "Research on Resistor-Loaded HalfEllipse Antenna System for GPR Application", International Journal of Antennas and Propagation, p. 7917985, 2016. https://doi.org/10.1155/2016/7917985

[18] Dokjok, N., Thaiwirot, W., Boonpoonga, A. "A compact strip-loaded slot antenna with feeding strip and blended stub for GPR applications", In: 14th International Conference on Electrical Engineering/ Electronics, Computer, Telecommunications and Information Technology (ECTI-CON), Phuket, Thailand, 2017, pp. 481-484. https://doi.org/10.1109/ecticon.2017.8096279
[19] Kundu, S., Jana, S. K. "A compact umbrella shaped UWB antenna for ground-coupling GPR application", Microwave and Optical Technology Letters, 60(1), pp. 146-151, 2018. https://doi.org/10.1002/mop.30928

[20] Zhong, Z.-P., Liang, J.-J., Fan, M.-L., Huang, G.-L., He, W., Chen, X.-C., Yuan, T. "A compact CPW-fed UWB antenna with quadruple rejected bands", Microwave and Optical Technology Letters, 61(12), pp. 2795-2800, 2019.

https://doi.org/10.1002/mop.31976 